\title{
Referential practices. Effects of a museum guide robot suggesting a deictic 'repair' action to visitors attempting to orient to an exhibit *
}

\author{
Karola Pitsch, Timo Dankert, Raphaela Gehle, and Sebastian Wrede
}

\begin{abstract}
An autonomous robot system was equipped with basic means to monitor the users' success/failure in following a robot's verbal-gestural deictic reference to an object and - in case of problems - to provide additional help, i.e. to suggest a 'repair' action. A real-world field trial with the robot acting as museum guide constitutes the basis for analysis of the users' reactions to the first reference and the subsequent 'repair' action in two structurally different conditions. Results indicate that deictic 'repair' actions are mostly successful helping users to correctly orient, but they may also lead to confusion for initially correctly oriented visitors in situations of small groups of users. A recurring user practice is revealed which consists of displaying to co-visitors their understanding of the reference by pointing to the location and thus providing additional orientational help.
\end{abstract}

\section{INTRODUCTION}

When robots interact with humans in a meaningful environment, a central functionality for the robot consists in orienting the users to specific objects in the surround. This is relevant e.g. in the case of shop assistants, household companions or for a robotic museum guide which needs to orient visitors to exhibits when providing information $[5,8,9$, 14]. While most approaches in HRI have considered such deictic (or: referential) practices as an individualistic task of the speaker, [8] reveal the difficulties visitors experience when attempting to follow a robot's reference to an exhibit in a realworld museum scenario: In some cases, they tend to orient to the wrong object realizing this problem only later, or they are confused and search for the correct reference during the robot's explanation. Such circumstances might render the users' understanding of the robot's explanations difficult. It is thus not sufficient to provide models for coordinating a robot's talk, head orientation, gestures etc. to enact the reference to an object. Additionally, specific procedures seem necessary which allow the robot to monitor the user's conduct and react on a more fine-grained level if she experiences problems. In this vein, [8] suggest to consider a robot's deictic practices as an act of interactional coordination, i.e. to equip the system with means to observe the users' reactions to the deictic references, to interpret these as success/failure and if needed to provide further referential hints, i.e. to initiate a 'repair' action.

Towards this aim of an interactional account of referential practices, we equip an autonomous robotic system with (a) means to observe the head orientation of multiple visitors and (b) a basic 'repair' strategy which provides, in case of assumed problems, additional information about the object indicated.

\footnotetext{
*The authors acknowledge the financial support from the Cluster of Excellence Cognitive Interaction Technology 'CITEC' (EXC 277) (IP-18 'Interactional Coordination and Incrementality in HRI') and from the Volkswagen Foundation (Dilthey Fellowship 'Interaction and Space')

$\mathrm{K}$. Pitsch is with the University of Duisburg-Essen, Institute of Communication Studies, karola.pitsch@uni-due.de (corresponding author;
}

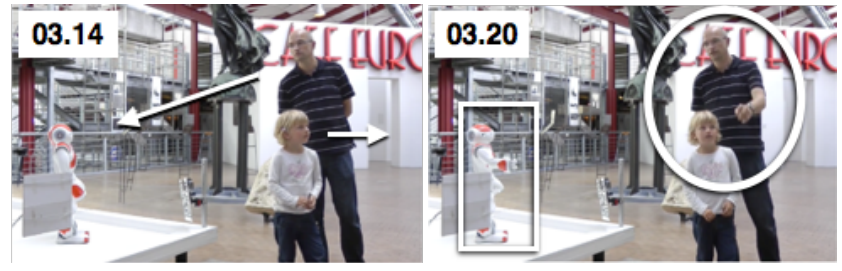

Figure 1. Monitoring success/failure of deictic referenc \& initiating repair

In this paper, we present initial analysis of video-taped recordings from a field trial with an early prototype of the autonomous system. A small-sized humanoid NAO robot (Aldebaran, V4) was set up to act as guide in the local museum in order to explore the ways in which the visitors would react to the system's referential practices, particularly when it would suggest a 'repair' action, whether interactionally adequate or not. We address the following question:

(1) How do the visitors react to the robot's deictic reference under different situational-structural conditions? (2) How do visitors react if the robot treats their conduct as problematic and offers a second referential hint, i.e. undertakes a deictic 'repair'? (3) Given that such attempts of interactional coordination are highly challenging for a technical system: How do visitors deal with cases of the robot misinterpreting the situation and offering a repair although it is inadequate?

Initial results of a combined qualitative and quantitative explorative analysis of video-recorded data from humanrobot-interaction (HRI) during a field trial with an autonomous robot system are presented. They constitute the basis for design considerations of robot deixis towards enabling technical systems to engage in sequential action with humans.

\section{Deictic (OR: Referential) Practices IN HRI}

To understand locational deixis and referential practices an important body of work has been undertaken to enable technical systems to detect human deictic gestures and to determine the gesture's target [4]. For the production of deictic reference, verbal approaches in NLG [6] and multimodal accounts considering the choice of modalities (talk, gesture head, orientation) and their intra-personal coordination have been explored in robotics and ECAs. The effectiveness of specific strategies has been investigated for robotic systems in laboratory studies showing that a combined 'head and arm movement' is more successful in indicating a location than are single modalities [12]. And the user's perception of accuracy

KP has conducted the analysis, written the text and devised the robot's deictic practices. TD has programmed the robotic system; all authors have collaborated preparing and conducting the study) Sebastian Wrede and Timo Dankert are with CITEC. Raphaela Gehle is with the University of DuisburgEssen, Institute of Communication Studies. 
of pointing gestures under different conditions (normal, distant, clustered objects, noise) for touching the object vs. sweeping/grouping gestures has been determined [10]. First attempts to take into consideration the recipient in referential practices, have been made for a robot giving route directions. [4] designed a robot's pauses between sentences based on previously measuring the time that a listener needs to understand and process a robot's sentence in a similar situation. In the experiment, the best ratings (using questionnaires) were indeed achieved with a robot using gestures and fixed listener-modeled pause duration even though their length exceeded the common pause timing. [7] investigate deictic reference in a museum guide robot under real-world conditions, and find that their success ranges initially between $25 \%$ and $80 \%$ and show using video-based case analysis how these difficulties are interactionally produced. As result they suggest an interactional approach to robot deixis: The robot should monitor the visitors' success/failure in following its deictic reference, and - if the visitors experience difficulties - the robot should provide additional referential hints, i.e. to initiate a 'repair' action. This approach is opposed to the idea of one-way communication. It is inspired by Conversation Analytic research on deictic practices in human social interaction showing to which extent a speaker's multimodal deictic reference is co-produced by the recipient [3]. In this study, we take the ideas suggested in [8] further and equip an autonomous robot system with basic means for interactional coordination in referential practices, to explore its ways of functioning and the users' reactions to it in a field trial.

\section{DESIGN OF THE RoBOT's REFERENTIAL PRACTICES: OFFERING 'REPAIR' IN CASE OF TROUBLE}

To explore interactional strategies of deictic object reference, a set of structurally different situations was implemented in the scenario of a robotic museum guide. The robot's explanation included five instances of referring actions to an exhibit, for three of which a basic 'repair' functionality was implemented. For analysis in this paper, two situations are considered which differ in their interactional complexity. As these instances follow the course of the robot's explanation and are explorative in nature, they are not counter-balanced.

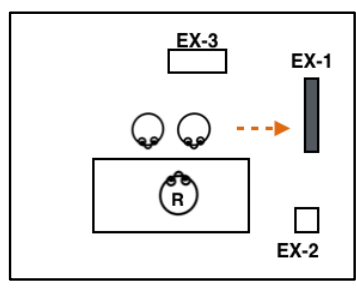

Condition 1

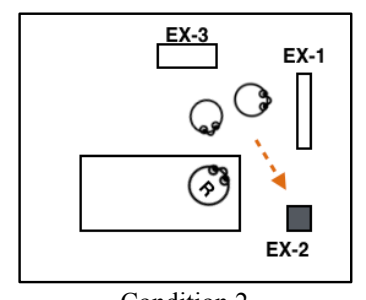

Condition 2
Figure 2. Interactional conditions when referring to an exhibit

\section{A. Condition 1 (Basic): Deictic reference to an easily detectable object \& visitors oriented to robot}

Condition 1 is designed as a straight forward basic situation of referring to an object, which occurs directly after human and robot entered in contact with each other. The participants are assumed to be attentive and oriented to the robot, the robot verbally introduces a new topic/referent and then suggests to orient to an exhibit - located nearby at about $90^{\circ}$ (Fig. 1a: EX-1) - which shows (features of) this content. (a) Initial context: After getting in contact with the visitors, the robot - orienting its head to the visitors vis-à-vis - verbally introduces as topic the local castle.

(b) First reference to the object: Then, the robot starts with a deictic expression "over there" and introduces as new referent the people "who used to live on the castle", which is accompanied by a deictic gesture to EX-1 (the robot's head remains oriented to the visitors).

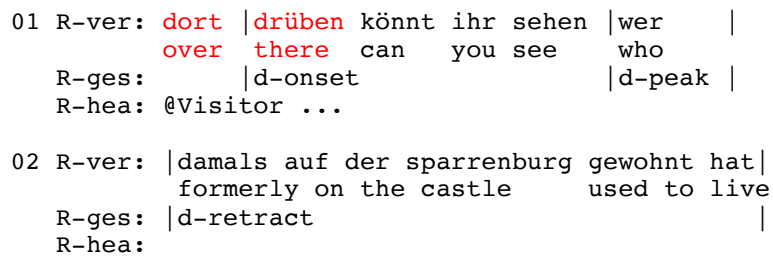

(c) Second reference to the object ('repair'): If, after the utterance line 01-02, the visitors remain oriented to the robot, it is assumed that they do not follow the robot's deictic reference. This causes the initiation of a second reference to the object (1. 04-05). This 'repair' action is designed to be more explicit, i.e. as an upgrade: verbally, the referent is named more explicitly ("on the big picture") and the robot's head is in addition to the deictic gesture - rotated towards EX-1.

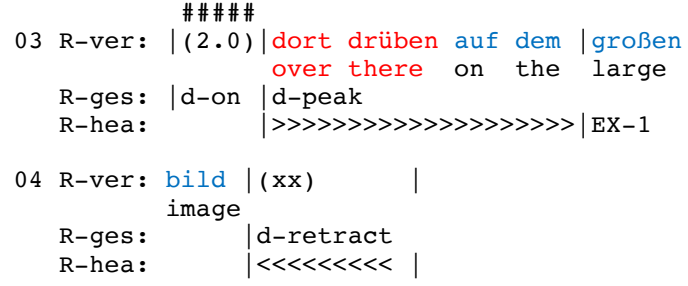

Note that the design of the robot's 'first reference to the object' is influenced by the system's need to detect and track the users in real-time on a fine-grained basis. Therefore, the robot's head - where its camera is located - had to be oriented to face the visitors, and could not be used to point to the object during the first reference, as humans would normally do. Thus, to ensure that the robot could monitor its environment is consequential for the design of the its interactional conduct.

\section{B. Condition 2 (Complex): Deictic reference leaving space for interpretation \& visitors with varying orientation}

Condition 2 is designed as a more complex instance of referring to an object which occurs as fourth instance of the deictic references: (i) The participants are expected to be oriented either to the robot or to EX-1. (ii) As they are already involved with an exhibit (EX-1) and the first deictic reference leaves space for interpretation, they could reasonably assume that the robot's new reference might be a feature of EX-1 instead of constituting a self-standing new exhibit EX-2.

(a) Initial context: The robot has introduced the earls of the local castle, has made the visitors search for specific objects on EX-1 - such as sword and shield - and points out that such a sword has been found during an archeological excavation on the old market of the town.

(b) First reference to the object: Then, the robot starts with a deictic expression "over there" and names the location in the room "socle" where the sword can be found, accompanied by a deictic gesture towards EX-2. 


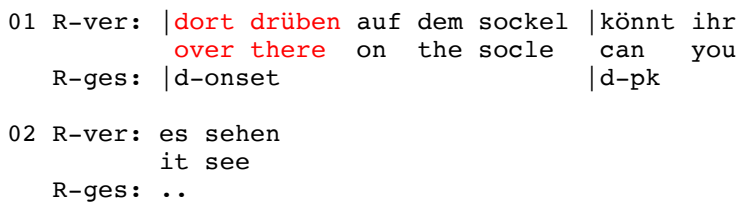

(c) Second reference to the object ('repair'): If, after the utterance line 01-02, the visitors remain oriented to the robot, it is assumed that they do not follow the robot's deictic reference. This causes the initiation of a second reference to the object (1. 04-05). This 'repair' action is designed to be more explicit, i.e. as an upgrade: verbally, the referent is named more explicitly ("in the corner") disambiguating it as a new free-standing object EX-2 as opposed to being a feature of EX1. Also, the robot's head is - in addition to the deictic gesture - rotated towards EX-2.

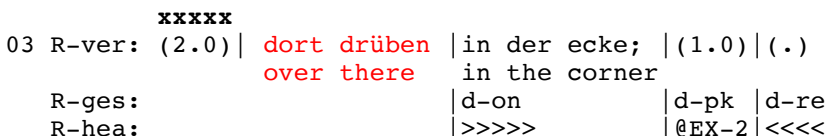

\section{Monitoring of visitor conduct and initiation of repair}

The robot continuously monitored its environment for faces, i.e. potential interaction partners, and used this information to decide whether a 'repair' action should be initiated. After having produced the 'first reference to the object', the robot checks the visitors' head orientation and makes the following decision: If the head orientation of more interaction partners or an equal amount is oriented in the 'wrong' direction than in the correct one, the robot initiates a 'repair' action, i.e. the 'second reference'. The moment of the robot's 'checking' is marked in the action scripts above as \#\#.

\section{Robot SYSTEM}

As the robotic platform should provide intuitive access for lay-users and be robust enough to be deployed in the real world, a humanoid NAO robot (Aldebaran, V4, $58 \mathrm{~cm}$ high) was used and set up to run autonomously. It was based on a set of modularized system components organized by a dedicated middleware architecture [13]. For the functions investigated here, the following components are important:

Perception: The system's functions relied on the perceptual results from the robot's internal VGA camera(s) and an external microphone positioned on a table. The system detected and tracked the visitors' heads using the OpenCV library and processed this information to build its hypotheses about interaction partners and group size in a dedicated person manager. The visitors' head orientation and rotation was detected by a specific VFOA component [1], on the basis of which the system classified their focus of attention in "at Nao" and "unfocused". This information was used for the robot's monitoring during the referential practices to decide whether a repair action was required.

Dialogue: The robot's multimodal utterances consisted of preconfigured, synchronized speech-gesture-(head orientation) behaviors, which occurred in a fixed order during the robot's explanation. A dedicated dialogue component [7] was used in combination with a finite state-machine.

\section{STUDY AND DATA}

A field trial was conducted at Bielefeld Historical Museum.

\section{A. Study}

The robot was set up to act as a museum guide and was positioned in an open space of the museum alongside a set of exhibits from the museum's Middle Ages collection to which the robot referred during its explanation [2]. To compensate for its small size $(58 \mathrm{~cm})$, it was placed on a table $(1.20 \times 2 \mathrm{~m}$, $0.7 \mathrm{~m}$ high). It was set up to get in contact with visitors $[6,8]$, to give explanations about three different objects, walk across the table, involve visitors in a small question/answer sequence, and to close the encounter. Trials lasted for about 4 minutes.

The trial was co-located with the local Science Festival 'Geniale' so that users of the system were groups of 2 to 5 visitors comprised of adults and children curious about robots. Yet, they have not been exposed to robots previously. Prior to entering the robot space, visitors were informed that they would be video-recorded and written consent was obtained. Yet, they were not informed about the specific nature of the study nor how to handle the robot. After the trial, the research team was available to answer questions. The study took place during two consecutive week-end days, with each day divided into a morning and an afternoon slot of about 3 hours each.

\section{B. Data}

In total, 72 runs of HRI with mostly 2 to 5 participants each were recorded with 4 external HD video cameras. During the last slot, also the robot's internal data was recorded, i.e. the VGA stream from the robot's head camera as well as logfiles of the system's calculations. Additionally, the visitors' conduct was recorded with two Kinect motion capture cameras (not connected to the robotic system) to provide a basis for offline analysis. For analysis in this paper, we focus on the data from the last slot providing both the system internal and the external perspective. From the 23 recorded trials obtained with this combined data set, a sub-corpus of 14 cases (with 49 participants in total) is considered for analysis here as we excluded trials with expert users, large groups and runs during which members of the team provided explanations to visitors.

The system's algorithms decided for all of the 14 trials both for condition 1 and 2 that a second reference to the exhibit was required and provided a 'repair' action (Table I and II). This is partly due to the implementation of the algorithm for initiating repair (see III.C) and partly due to the insecurity of perception under the highly challenging conditions. For our analysis of the visitors' interpretation of the robot's conduct, this circumstance provides for systematic empirical data.

\section{ANALYTICAL METHOD}

The video data is analyzed with a combined qualitative and quantitative approach. The qualitative analysis is methodologically based on Conversation Analysis (CA) and its multimodal extensions [11] and allows to gain insights into the sequential structure and the micro-processes involved in the interaction between human and robot. For quantitative analysis specific aspects of the interactional conduct were extracted and systematically registered in order to obtain an overview of the overall relevance of phenomena. 


\section{CONDITION 1: BASIC SITUATION}

In the basic condition, the robot provides a deictic reference to an easily detectable object and visitors are most likely to be oriented to the robot at that moment.

\section{A. Quantification: Mostly situationally inadequate 'repair'}

Investigation of the visitors' reactions in the 'basic' condition reveals that $91 \%$ of the participants (i.e. 45 out 49 ) follow the robot's first referential hint to EX-1 during or at the end of the robot's utterance, while $8 \%$ of the participants (4 out of 49) do not follow the reference (Table I). We count 'follow the robot's orientation' here when a participant turns (both momentarily or longer) her head in the direction of the exhibit after the robot has produced the deictic reference. From these 45 cases of the robot's successful first reference, 4 participants don't follow the robot's deictic reference, but are instead helped by another visitor. Given that the robot provides a 'repair' action in all situations, this leads to 45 cases of 'inadequate repair' and 4 cases of 'requiring repair'.

TABLE I. CONDITION 1 (BASIC) - For EXPLANATIONS SEE ANNEX

\begin{tabular}{|c|c|c|c|c|c|}
\hline & Number & $\begin{array}{c}\text { f visitors ori } \\
\text { EX-1 ... }\end{array}$ & ing to & $\begin{array}{c}\text { No. of } \\
\text { visitors }\end{array}$ & $\begin{array}{c}\text { Effect of } \\
\text { robot's }\end{array}$ \\
\hline $\begin{array}{l}\text { No. of } \\
\text { Trial }\end{array}$ & $\begin{array}{l}\text { until end } \\
\text { of } 1^{\text {st }} \text { utt. }\end{array}$ & $\begin{array}{l}\text { with aid of } \\
\text { co-partici- } \\
\text { pant (gest.) }\end{array}$ & $\begin{array}{l}\text { before } \\
\text { repair }\end{array}$ & $\begin{array}{l}\text { who } \\
\text { require } \\
\text { repair }\end{array}$ & $\begin{array}{l}\text { repair } \\
\text { action }\end{array}$ \\
\hline $\begin{array}{l}4-002 \\
(\overline{2}) 1+1\end{array}$ & 1 & $1(\mathrm{C})$ & $\begin{array}{l}2 \\
(100 \%)\end{array}$ & -- & $\checkmark$ \\
\hline $\begin{array}{l}4-003 \\
\text { (4) } 2+2\end{array}$ & 4 & -- & $\begin{array}{l}4 \\
(100 \%)\end{array}$ & -- & $\checkmark$ \\
\hline $\begin{array}{l}\text { 4_004 } \\
\text { (3) } 2+1\end{array}$ & 3 & -- & $\begin{array}{l}3 \\
(100 \%)\end{array}$ & -- & $\begin{array}{l}\text { 1x conf. } \\
\text { P points }\end{array}$ \\
\hline $\begin{array}{l}4-005 \\
(5) 2+3\end{array}$ & 4 & -- & $\begin{array}{l}4 \\
(80 \%)\end{array}$ & $\begin{array}{l}1(\mathrm{~A}) \\
(20 \%)\end{array}$ & $\begin{array}{l}1 \text { (A) } \checkmark \\
4 \text { okay }\end{array}$ \\
\hline $\begin{array}{l}\text { 4_006 } \\
\text { (2) } 2\end{array}$ & 2 & -- & $\begin{array}{l}2 \\
(100 \%)\end{array}$ & -- & $\checkmark$ \\
\hline $\begin{array}{l}4-007 \\
\text { (3) } 1+2\end{array}$ & 2 & -- & $\begin{array}{l}2 \\
(66 \%)\end{array}$ & $\begin{array}{l}1(\mathrm{C}) \\
(33 \%)\end{array}$ & $\begin{array}{l}1(\mathrm{C})^{\checkmark} \\
1 \text { okay }\end{array}$ \\
\hline $\begin{array}{l}4 \_008 \\
\text { (3) } 2+1\end{array}$ & 2 & $1(\mathrm{C})$ & $\begin{array}{l}3 \\
(100 \%)\end{array}$ & -- & $\checkmark$ \\
\hline $\begin{array}{l}4009 \\
\text { (6) } 3+3\end{array}$ & 6 & -- & $\begin{array}{l}6 \\
(100 \%)\end{array}$ & -- & $\begin{array}{l}\checkmark \\
\text { search }\end{array}$ \\
\hline $\begin{array}{l}\text { 4_010 } \\
\text { (2) } 1+1\end{array}$ & 2 & -- & $\begin{array}{l}2 \\
(100 \%)\end{array}$ & -- & $\begin{array}{l}\checkmark \\
\text { gaze diff. }\end{array}$ \\
\hline $\begin{array}{l}4-016 \\
(\overline{6}) 4+2\end{array}$ & 4 & $2(X)$ & $\begin{array}{l}6 \\
(100 \%)\end{array}$ & -- & $\checkmark$ \\
\hline $\begin{array}{l}40018 \\
(\overline{2}) 2\end{array}$ & 2 & -- & $\begin{array}{l}2 \\
(100 \%)\end{array}$ & -- & $\begin{array}{l}\checkmark \\
\text { body or. }\end{array}$ \\
\hline $\begin{array}{l}4-019 \\
(\overline{5}) 3+2\end{array}$ & 4 & -- & $\begin{array}{l}4 \\
(80 \%)\end{array}$ & $\begin{array}{l}1 \\
(20 \%)\end{array}$ & $\begin{array}{l}\checkmark \\
\text { search }\end{array}$ \\
\hline $\begin{array}{l}4 \_020 \\
(\overline{2})\end{array}$ & 1 & -- & $\begin{array}{l}1 \\
(50 \%)\end{array}$ & $\begin{array}{l}1 \\
(50 \%)\end{array}$ & $\begin{array}{l}1)^{\checkmark} \\
1 \text { okay }\end{array}$ \\
\hline $\begin{array}{l}4-022 \\
\text { (4) } 2+2\end{array}$ & 4 & P deict. gest. & $\begin{array}{l}4 \\
(100 \%)\end{array}$ & -- & $\begin{array}{l}4 \text { search, } \\
\text { confusion }\end{array}$ \\
\hline $\begin{array}{l}49 \text { Part } \\
(100 \%)\end{array}$ & & & $\begin{array}{l}45 \\
(91 \%)\end{array}$ & $\begin{array}{l}4 \\
(8 \%)\end{array}$ & \\
\hline
\end{tabular}

Figure 3. Providing referential repair. Necessity and Effect (Condition 1)

Further investigation of the effects of the robot's repair actions reveals: (a) From the four cases requiring repair, four turn out to be successful for the non-oriented participant; but for one visitor who initially followed correctly the robot's reference, this leads to confusion. (b) For the inadequate repair, in 3 out of 10 trials it turns out to be problematic for the participants with these visitors showing signs of confusion and search behavior. These observations invite to investigate further how the confusions are interactionally produced and what the robot's perspective internal perspective might be.
To answer these questions, qualitative explorative analysis is conducted unpacking the interactional organization.

\section{B. Case Analysis 1 (successful): Re-Orientation}

Observer's (external) perspective: We begin the explorative analysis with a case of a successful repair. In our fragment (trial 4_007) three visitors (one adult, two children) are positioned vis-à-vis the robot and attentively oriented to it (\#38.26, first row of video stills). The robot invites them - via talk and gesture (\#38.26, 1.01-02) - to inspect exhibit 1 to its right hand side. The visitors V1 and V2 immediately follow this offer, only V3 remains focused on the robot (\#40.78). During this time, the robot's perceptual modules detect relatively stable (at least) V3 and correctly identify it as oriented "at Nao" (\#38.26, 40.78 second row of video stills showing the robot's internal perspective of the same situation).

$$
\begin{aligned}
& 01 \text { R-ver: |dort | drüben könnt ihr sehen | wer } \\
& \text { over there can you see }
\end{aligned}
$$

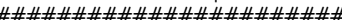

02 R-ver: |damals auf der sparrenburg gewohnt hat formerly on the castle used to live R-ges: |d-retract

R-hea: ...

40.78
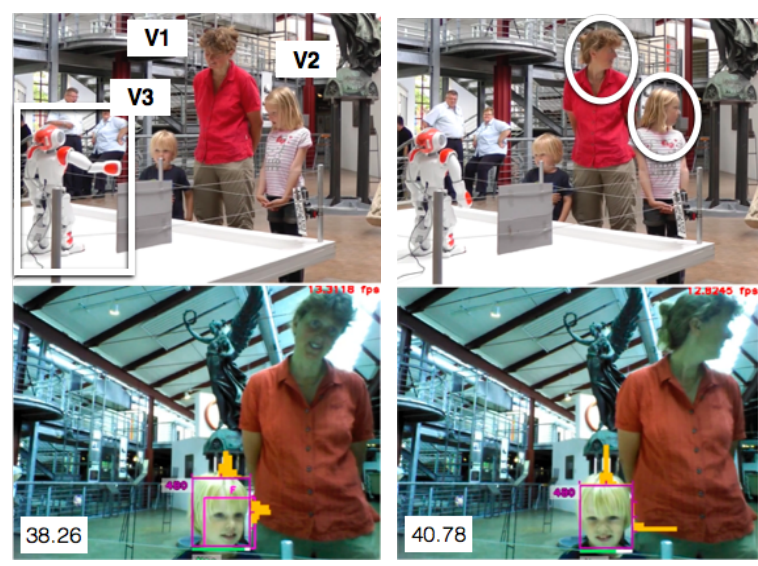

The system correctly identifies this situation as requiring 'repair' and produces a second orientational hint to exhibit 1, this time produced as verbal and gestural upgrade rotating also its head (\#45.22, 1.03-04). Immediately after this, also V3 turns his head and body in the direction indicated (\#46.78). This way, the autonomous system successfully helps to bring V3 in a position as to follow the robot's explanation of exhibit 1 .
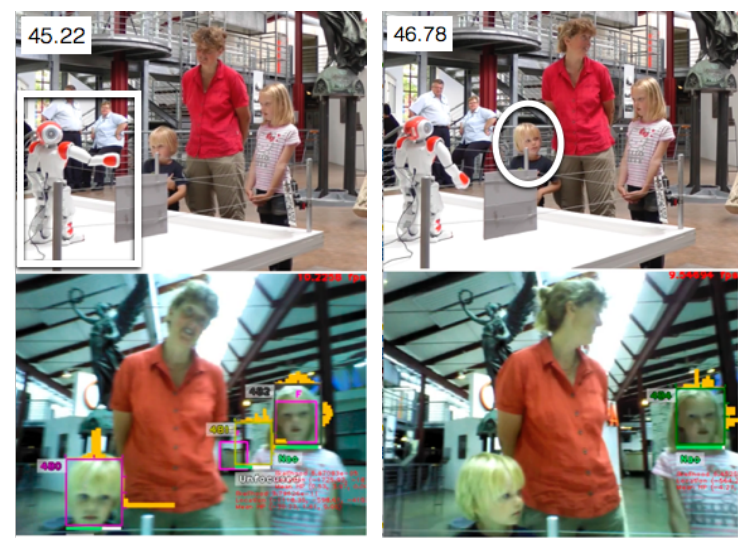
03 R-ver: | (xx) | dort drüben auf dem |großen over there on the large

R-ges: |d-on |d-peak

R-hea: $|>>>>>>>>>>>>>>>>>| E X-1$

04 R-ver: bild |(1.5) |

R-ges: image $\mid$ d-retract

R-hea: $\quad|<<<<<<<<<|$

Robot's internal perspective: Despite the success of the robot's conduct in providing a timely 'repair' action at a relevant moment and its valuable outcome as shown above, this same situation considered from the robot's internal perspective, reveals a set of limitations of the current system.

(a) Number of participants: Three participants gather in front of the robot (e.g. \#38.26 first row of stills). Yet, in the field of view provided by the robot's internal camera only 2 of them (e.g. \#38.26 second row of stills) are visible; the implemented person detection only discovers 1 person. Thus, this situation appears for the robot as a 1:1 while, in reality, it would have to deal with a group of participants.

(b) Managing participation: When the robot rotates its head towards its right side during the second deictic reference, all three people are located in the camera's field of view (\#45.22 second row). The person detection now correctly 'looses' the boy's face when he - as intended - turns to face the exhibit (\#47.78). In the meantime, however, the system has detected also a second person (young girl, \#45.22., \#46.78), so that the group size - central to the robot's algorithmic decisions - becomes a difficult feature. The system thus needs dedicated means for keeping track of individual interaction partners over time if it was supposed to evaluate the success/failure of his actions and to capture the interactional dynamics involved.

\section{Case Analysis 2 (problematic): Confusion}

For case 1, we find four trials during which the robot's 'repair' action appears problematic in terms of its interactional effects and implications: Visitors, who managed to correctly follow the robot's reference to the indicated exhibit 1 , search for the object after the robot's 'repair' action and get confused.

Consider the following fragment showing case 1 (trial 4 004) and for which a more detailed analysis is provided in [9]. From the three visitors, V1 and V2 follow the robot's initial reference to exhibit 1 , while $\mathrm{V} 3$ continues to be focused on the robot itself (\#00.44.05; \#00.48.08). Immediately after V3 finally also orients to exhibit 1 (\#00.49.00), the robot provides the second reference. V3 reacts by turning back to the robot performing a pointing gesture (\#00.50.06) and appears to interpret it as a 'repair' of her last orientation (which was correctly to exhibit 1 ) as she turns round (\#00.53.10) and repeatedly embodies a search $(\# 00.58 .05)$. This sequential misplacement of the robot's 'repair' does not only leave V3 with confusion about the indicated referent, but it also - due to her searching - prevents her from understanding the robot's shift to a next action (walk to exhibit 2).

These consequences point to the need of considering the potential side effects of a robot attempting to engage in sequential interaction with individuals and groups of users. Firstly, we will have to think about the degree of interactional complexity which will be created once a technical system tries to pro-actively initiate repair actions. Secondly, the ways in which such troublesome situations are solved through other visitors helping the confused person confirms our approach of considering human(s) and robot as one "interactional system" which has to carry out an interactional task together [7].
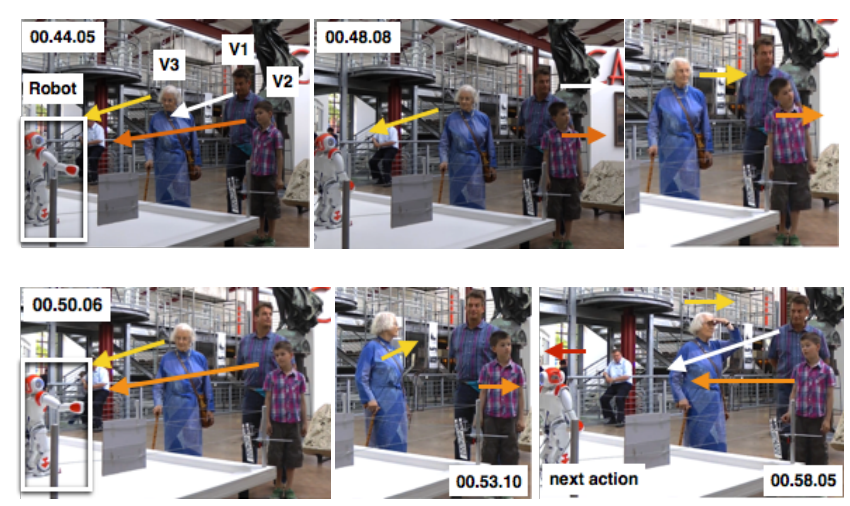

VIII. CONDITION 2: COMPLEX SituAtion

In the complex condition, the deictic reference leaves options for interpretation, and participants might have divergent foci of attention. A 'repair' action might be important.

A. Quantification: Mostly additional referential help needed

Investigation of the visitors' reactions in the 'complex' condition reveals that only $35 \%$ of the participants (i.e. 16 out 46) follow the robot's first referential hint to EX-2 during or at the end of the robot's utterance (exclusively adults).

TABLE II. CONDITION 2 (COMPLEX) - For EXPLANATION SEE ANNEX

\begin{tabular}{|c|c|c|c|c|c|}
\hline \multirow[b]{2}{*}{$\begin{array}{l}\text { No. of } \\
\text { Trial }\end{array}$} & \multicolumn{3}{|c|}{$\begin{array}{l}\text { Number of visitors orienting to } \\
\text { EX-2 ... }\end{array}$} & \multirow{2}{*}{$\begin{array}{c}\text { No. of } \\
\text { visitors } \\
\text { who } \\
\text { require } \\
\text { repair }\end{array}$} & \multirow{2}{*}{$\begin{array}{c}\text { Effect of } \\
\text { robot's } \\
\text { repair } \\
\text { action }\end{array}$} \\
\hline & $\begin{array}{l}\text { until end } \\
\text { of } 1^{\text {st }} \text { utt. }\end{array}$ & $\begin{array}{l}\text { with aid of } \\
\text { co-partici- } \\
\text { pant (gest.) }\end{array}$ & $\begin{array}{l}\text { before } \\
\text { repair }\end{array}$ & & \\
\hline $\begin{array}{l}4-002 \\
(\overline{2}) 1+1\end{array}$ & -- & - & -- & $2(100 \%)$ & $\begin{array}{l}\checkmark \\
\text { P points }\end{array}$ \\
\hline $\begin{array}{l}4-003 \\
(\overline{4}) 2+2\end{array}$ & $1(\mathrm{~A})$ & -- & 1 & $3(75 \%)$ & $\begin{array}{l}\checkmark \checkmark \\
\text { P points }\end{array}$ \\
\hline $\begin{array}{l}4-004 \\
(3) 2+1\end{array}$ & $1(\mathrm{~A})$ & -- & 1 & $2(66 \%)$ & P points \\
\hline $\begin{array}{l}4-005 \\
(5) 2+3\end{array}$ & $1(\mathrm{~A})$ & -- & 1 & $4(80 \%)$ & $\begin{array}{l} \\
\text { P point }\end{array}$ \\
\hline $\begin{array}{l}4-006 \\
(2) 2\end{array}$ & -- & -- & -- & $2(100 \%)$ & $\begin{array}{l}\text { No or. to } \\
\text { EX-2 }\end{array}$ \\
\hline (3) $1+2$ & -- & -- & -- & $3(100 \%)$ & $\begin{array}{l}\checkmark \\
\text { P point }\end{array}$ \\
\hline $\begin{array}{l}4-008 \\
\text { (3) } 2+1\end{array}$ & $2(\mathrm{~A})$ & $1(\mathrm{C})$ & 3 & -- & $\checkmark$ \\
\hline $\begin{array}{l}4-009 \\
(\overline{6}) 3+3\end{array}$ & $1(\mathrm{~A})$ & $\begin{array}{l}\text { P points, not } \\
\text { oriented to }\end{array}$ & 1 & $5(66 \%)$ & $\checkmark$ \\
\hline $\begin{array}{l}4-010 \\
(2) 1+1\end{array}$ & $1(\mathrm{~A})$ & -- & 1 & $1(50 \%)$ & $\begin{array}{l} \\
\text { P points }\end{array}$ \\
\hline $\begin{array}{l}4-016 \\
(\overline{6}) 4+2\end{array}$ & $1(\mathrm{~A})$ & $\begin{array}{l}5-\mathrm{P} \text { points } \\
\text { before } \mathrm{R}\end{array}$ & 6 & -- & P points \\
\hline $\begin{array}{l}4 \_018 \\
(\overline{2}) 2\end{array}$ & -- & -- & -- & $2(100 \%)$ & $\begin{array}{l}\text { No or. to } \\
\text { EX-2 }\end{array}$ \\
\hline $\begin{array}{l}4-019 \\
(\overline{5}) 3+2\end{array}$ & -- & -- & -- & $5(100 \%)$ & $\begin{array}{l}\checkmark \\
\text { P point }\end{array}$ \\
\hline \multicolumn{6}{|l|}{ 4_020 } \\
\hline $\begin{array}{l}4-022 \\
(\overline{3}) 1+2\end{array}$ & $1(\mathrm{~A})$ & $1(\mathrm{C})$ & 2 & $1(66 \%)$ & $\checkmark$ \\
\hline $\begin{array}{l}46 \text { Part } \\
(100 \%)\end{array}$ & & & $\begin{array}{l}\text { 16 Part } \\
(35 \%)\end{array}$ & $\begin{array}{l}\text { 30 Part } \\
(65 \%)\end{array}$ & $\begin{array}{l}8 / 14 \\
\text { P point }\end{array}$ \\
\hline
\end{tabular}

Figure 4. Providing referential repair. Necessity and Effect (Condition 2) 
In three trials, a child does not follow the robot's reference, but is helped by an adult. Thus, in $65 \%$ of the cases (i.e. 30 participant cases or 11 trials) the visitors indeed need further information to orient to the correct to be able to relate the robot's explanations in a meaningful way to the corresponding exhibit (Table II).

Further investigation of the effect of the robot's 'repair' actions reveals that they are successful in helping the visitor to afterwards orient to the right object in 9 trials while they are not in only 2 trials. The question arises: How is the interaction organized? How does the group play into these effects?

\section{B. Case Analysis (successful): Re-Orientation \& Pointing}

In this complex case, the visitors are mostly positioned in (a triangle) between the robot and exhibit 1, and orient their heads between these two locations when following the robot's explanations. In our fragment (trial 4 002), the video still at the beginning of the robot's reference shows this situation with $\mathrm{V} 1$ oriented to the robot, and V2 oriented to the exhibit (\#03.14). The perspective from the robot's internal camera also gives a sense of the challenge for the system to identify $\mathrm{V} 1$ and V2 as interaction partners on the basis of the VGA camera sensor only. When the robot produces the initial reference to exhibit 2 (line 01-02), V1 turns back to exhibit 1 and seems to scrutinize it for the previously introduced referent 'sword' (\#03.16 to \#03.18 V1's head orientation).

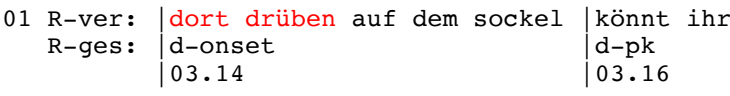

02 R-ver: es sehen R-ges: ..
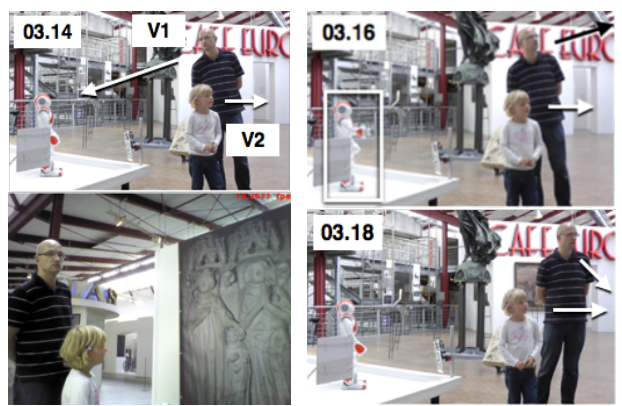

The system identifies this situation (correctly) as requiring 'repair' and produces a second reference to exhibit 2, which is designed as an upgrade and now includes also the robot's head turn towards the exhibit (line 4, \#03.19.a, \#03.19.b, \#03.20, $\# 03.21$ ). The video recordings reveal that V1 and V2 exhibit different strategies when they react to the robot's utterance:

- The child V2 turns back to look at the robot (\#03.19.a), sees its upcoming deictic gesture and head orientation (\#03.19.b) and begins to gaze-follow these hints (\#03.20).

- The adult V1 begins to shift his head in the direction of exhibit 2/robot (\#03.19.a), stops his head movement and begins to raise his left arm towards exhibit 2 (\#03.19.b). Then, while bringing his gesture in the visual field of V1, he looks at the robot (\#03.20).

For V2, her movement of gaze-following the robot's deictic reference co-occurs with V1's deictic gesture towards exhibit 2 (which, itself is dynamically shaped to be positioned in V1's shifting visual field). On this basis, V2 lifts her head in the direction of the sword (\#03.21). This way, the robot's suggestion of 'repair' successfully helps to bring both V1 and $\mathrm{V} 2$ in a position to follow the explanation of exhibit 2.
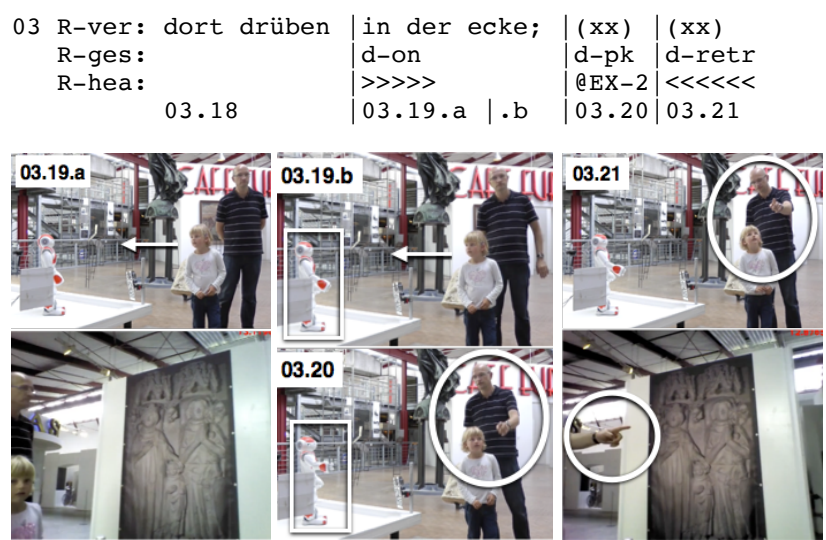

Thus, in this situation (as well as in 7 further trials of this condition, see Table II) the visitors collaborate to identify the correct referent after the robot's second referential hint. By pointing they both visibly display their understanding of the robot's reference and design it as help to the other visitors. Such recurrent user practice - based on dynamics between the visitors - constitute an interesting observation for enabling the robot to monitor the effects of its actions: If it was able to detect pointing gestures (see the robot's perspective in \#03.21), it might gain an additional resource to build hypotheses about the visitors' engagement in attempting to follow the robot's explanations.

\section{SUMMARY AND IMPLICATIONS}

In this paper, we have suggested an interactional account of referential practices for a robotic system. Taking the observations presented in [7] further, we have developed a research prototype of an autonomous robotic museum guide and equipped it with (a) means to observe the head orientation of multiple visitors and (b) a basic 'repair' strategy which provides - in case of assumed problems - additional information about the object indicated. A field trial was conducted in a real-world historical museum and obtained a data set in which - for two structurally different conditions - the system's algorithms decided that a second reference to the exhibit was required and provided a 'repair' action. This provides for systematic empirical data for analyzing the visitors' reactions to the robot's conduct using a combined qualitativequantitative approach based on system-internal and external video data of users interacting with the robot.

Analysis leads to the following findings and implications:

Different practical needs \& understanding the moments when 'repair' actions are required: In the basic condition (1), only in $4(8 \%)$ out of 49 cases a robotic 'repair' action was required after the first reference to the object. This resulted in 45 cases $(91 \%)$ of interactionally inadequate repair. In the complex condition (2), in $30(65 \%)$ out of 48 cases a robotic 'repair' action was required with 16 cases $(35 \%)$ of interactionally inadequate repair. - Implications: These observations provide a first rough notion of likelihood for the need 
of repair which might be usable as a parameter for the design of algorithms in case of doubt how the system should interpret the users' conduct in situations of deictic reference to an object. At the same time, this calls for providing better empirical descriptions and systematization to determine the circumstances when a 'repair' action would be required.

Understanding the consequences of 'repair' actions: In the basic condition (1), for the 4 cases requiring repair, they were successful in all 4 occasions for the person in need of orientational help, but they confused 1 co-participant (as part of a group) who initially correctly followed the robot's reference. For the cases of inadequate 'repair', in 3 out of 10 trials this lead to confusion of some visitors who began to search for the corresponding object although they had been correctly oriented to it initially. In the complex condition (2), for the 30 cases requiring additional help, the robot's 'repair' action was successful in providing orientational resources for the visitors in most cases. Yet, in two trials the 'repair' action was not successful. The inadequate 'repair' action did not seem to produce much problems for the users. - Implications: For the situations of inadequate 'repair', the differences in condition 1 and 2 in that they lead to confusion vs. produce not much harm, call for a better understanding of the interactional circumstances and sequential conditions involved in the 'repair' actions. Further investigation is needed with regard to the timing of actions, the concrete combination of the robot's talk, gesture, head orientation etc. and the influence of participants being part of a group. We should also consider in which ways a robotic system might be able to deal with the consequences of its own 'repair' actions.

Visitor strategies when following the robot's deictic ('repair') action: The explorative qualitative analysis revealed two different strategies in following a robot's deictic reference, which consist (a) of following step by step the orientational hints or (b) of using the robot's deictic reference as an initiation to search for the correct referent by themselves.

Dissecting the notion of 'group': Visitors came in small groups to interact with the robot, and the qualitative analysis shows that the individual receives help from the other participants. For the robot's first deictic reference, this is the case in 3 trials for the basic condition (1), and in 5 trials for the complex condition (2). After the robot's second deictic reference (i.e. the 'repair' action), participants point to the correct object to help other visitors in 8 trials. In the basic condition (1), on the contrary, one of the confused participants showed his confusion via pointing (with others exhibiting a seemingly searching gaze behavior). - Implications: If a robotic system was able to detect the users' pointing gestures, it might gain some understanding of trouble and/or ongoing visitor dynamics in the case of deictic reference. Yet, further analysis would be required to differentiate between users exhibiting confusion vs. offers of help.

Enhancing the robot's perceptual capabilities: The explorative comparison between the robot's internal perception of the situation (using only its VGA camera) with the external observer's perspective revealed that the system considered situations as being those of $1: 1$ while the robot was confronted with a group of users, and stable person hypotheses over time were a challenge under the highly demanding conditions of a real-world situation. - Implications: Ways of integrating further sensor data should be considered.

\section{LIMITATIONS AND FUTURE WORK}

Limitations of the current study consist in the system's perceptual abilities related to the robotic platform. Also, the small size of the NAO robot might influence the users' abilities to follow its deictic references in space. Future work will consist in extending the empirical analysis of the HRI data, in enhancing the robot's perceptual capabilities and in refining the modeling of the 'repair' actions.

\section{ANNEX}

The tables I and II (section VI and VIII) show the different trials examined (no. of trial, first column) with their number in the data corpus, total number of participants (in brackets) and the number of adults and children in the visitor group (e.g. " $2+2$ "). The second, third and fourth column detail the number of visitors who orient to the exhibit indicated by the robot after the first reference, and when this happens - whether it occurs before the robot's 'repair' action and whether another participants help is involed. The fifths and sixths column detail whether a robotic 'repair' action is required and its effect.

\section{REFERENCES}

[1] Ba, S., \& Odobez, J.-M. (2009). Recognizing Visual Focus of Attention from Head Pose in Natural Meetings. IEEE Trans. On System, Man and Cybernetics: Part B, Cybernetics, 39:16-34.

[2] Gehle, R., Pitsch, K., Dankert, T., \& Wrede, S. (2015). Trouble-based group dynamics in real-world HRI - reactions on unexpected next moves of a museum guide robot. In Ro-Man 2015.

[3] Goodwin, C. (2003). Pointing as situated practice. In Pointing: Where language, culture and cognition meet (pp. 217-241). Mahwah, NJ: Lawrence Erlbaum.

[4] Lücking, A., Pfeiffer, T., \& Rieser, H. (2013). Pointing and reference reconsidered. International Journal of Corpus Linguistics, 56-79.

[5] Okuno, Y., Kanda, T., Imai, M., Ishiguro, H., \& Hagita, N. (2009). Providing route directions: Design of robot's utterance, gesture, and timing. In HRI 2009 (pp. 53-60).

[6] Paraboni, I. \& van Deemter, K. (2002). Generating Easy References. The Case of Document Deixis. In: INLG 2002, 6 p.

[7] Peltason, J., \& Wrede, B. (2010). Pamini: A framework for assembling mixed-initiative human-robot interaction from generic interaction patterns. In Proceedings of the 11 th annual meeting of the special interest group on discourse and dialogue (pp. 229-232).

[8] Pitsch, K., \& Wrede, S. (2014). When a robot orients visitors to an exhibit. Referential practices and interactional dynamics in real world HRI. In Ro-Man 2014 (pp. 36-42).

[9] Pitsch, K. (2015). Limits and opportunities for mathematizing communicational conduct for social robotics in the real-world? towards enabling a robot to make use of the human's competences. AI \& Society. doi:10.1007/s00146-015-0629-0.

[10] Sauppé, A., \& Mutlu, B. (2014). Robot deictics: How gesture and context shape referential communication. In HRI 2014.

[11] Sidnell, J. \& Stivers, T. (Ed.)(2013).The Handbook of Conversation Analysis. Chichester, West Sussex, UK: Wiley-Blackwell.

[12] St Clair, A., Mead, R., \& Mataric, M. J. (2011). Investigating the effects of visual saliency on deictic gesture production by a humanoid robot. In RO-MAN 2011 (pp. 210-216)

[13] Wienke, J., \& Wrede, S. (2011). A middleware for collaborative research in experimental robotics. In System integration (SII), 2011 IEEE/SICE international symposium on (pp. 1183-1190).

[14] Yamazaki, K., et al. (2009). Revealing Gauguin: Engaging visitors in robot guide's explanation in an art museum. In CHI 2009 (pp. 14371446). 


\section{DuEPublico}

This text is made available via DuEPublico, the institutional repository of the University of Duisburg-Essen. This version may eventually differ from another version distributed by a commercial publisher.

DOI: $\quad$ 10.1109/ROMAN.2016.7745135

URN: urn:nbn:de:hbz:464-20201221-163838-3

Accepted paper version of an article that was finally published in: 25th IEEE International Symposium on Robot and Human Interactive Communication (RO-MAN), New York, NY, 2016, pp. 225-231 doi: 10.1109/ROMAN.2016.7745135.

(C) 2016 IEEE. All rights reserved. Personal use of this material is permitted. Permission from IEEE must be obtained for all other uses. 